\title{
INFLUENCE OF VITAMIN B-12 COMPLEX INJECTION (ELDERVIT-12) ON GENTAMICIN NEPHROTOXICITY IN RATS: A PRELIMINARY STUDY
}

SHAIBU O. BELLO AND A. CHIKA

(Received 17 March 2008; Revision Accepted 11, November 2009)

\begin{abstract}
Objectives: To assess the effect of vitamin B-12 complex injection on the nephrotoxicity of gentamicin.

Design: Experimental study using a pre-validated model.

Subject: Adult Swiss albino rats weighing 140-214g, Generic gentamicin sulphate injection and Vitamin B-12complex injection containing $2500 \mathrm{mcg}$ Cyanocobalamin, $12 \mathrm{mg}$ Niacinamide, $0.7 \mathrm{mg}$ Folic acid and $150 \mathrm{mg}$ Ascorbic acid in twin ampoules to be combined fresh before administration.

Setting: A pharmacological research laboratory in a tertiary institute

Results: In Swiss albino rats, both $0.5 \mathrm{mls} / \mathrm{kg} /$ day and $1 \mathrm{mls} / \mathrm{kg} /$ day of B-12 complex injection for 5 days significantly and dose dependently exacerbated the increase in serum urea and creatinine caused by $80 \mathrm{mg} / \mathrm{k} /$ day of gentamicin while both doses of B-12 complex injection given for 10 days significantly and dose dependently ameliorated the increase in serum urea and creatinine caused by $80 \mathrm{mg} / \mathrm{k} /$ day of gentamicin (reversal of effect).

Conclusion: $0.5 \mathrm{mls} / \mathrm{kg} / \mathrm{day}$ of B-12 complex injection for 5 days exacerbated gentamicin nephrotoxicity while the same dose for longer duration or $1 \mathrm{ml} / \mathrm{kg} /$ day of B-12 complex ameliorated the toxicity. The exacerbation is probably due to the ascorbic acid component while the reversal is probably due to the other components acting directly or through a time dependent pharmacological advantage.
\end{abstract}

KEYWORDS: Gentamicin, toxicity, B-complex, ascorbic acid, rats

\section{INTRODUCTION}

The introduction of the aminoglycoside antibiotics to clinical medicine in 1944 (Gilbert, 1991) heralded an era of triumph over gram negative pathogens and, previously disastrous, sepsis. Nephrotoxicity and ototoxicity are continuing concerns with the use of this class of drug. Nephrotoxicity occurs in $10-20 \%$ of patients despite various preventive efforts including the use of longer interval dosing regimens and strict monitoring of drug levels (Gilbert, 1991). An antidote to aminoglycoside nephrotoxicity would be a welcome addition to these efforts. Gentamicin is amongst the most commonly prescribed aminoglycoside sand the one with extensive research aimed at illuminating its pathway to toxicity (Rybak and Ramkumar, 2007). Results of these studies suggest a redundant pathway to nephrotoxicity (Martinez-Salgado, et al., 2007) and this may be part of the explanation for the clinical failures of single antidotes. Furthermore, suggested antidotes like herbal extracts and calcium modulators are difficult to introduce for the sole purpose of prevention of nephrotoxicity. Safer antidotes with wide treatment experience may be easier to introduce into practice. Vitamin B-12 complex is a combination preparation of vitamin $B$ frequently used in the geriatric patients, who are also at increased risk of adverse drug effects. It is formulated as twin ampoules to be combined fresh before administration. One ampoule contains $2500 \mathrm{mcg}$ of Vitamin B-12 (Cyanocobalamin),
$12 \mathrm{mg}$ of B3 (Niacinamide) and $0.7 \mathrm{mg}$ of Folic acid in $1 \mathrm{mls}$ while the twin ampoule contains $150 \mathrm{mg}$ of Ascorbic acid (Vitamin C) in $1.5 \mathrm{mls}$. When combined for administration, the solution is $2.5 \mathrm{mls}$. This combination may interact with the renal effect of gentamicin and is probably nephroprotective because it contains antioxidants (Khadkhodaee, et al., 2007). This study was carried out to evaluate such nephroprotective properties.

\section{METHODS}

Adult, female, Swiss albino rats weighing140 to $214 \mathrm{~g}$ were obtained from the breeding unit of the Veterinary research institute, Vom, Nigeria and randomized into 4 groups of 4 rats each. The rats were housed in separate cages per group at a room temperature of $23 \pm 3^{\circ} \mathrm{C}$ and relative humidity of 53$60 \%, 12$ hours light and 12 hours darkness cycles, fed ad-libitum on water and standard chow, and acclimatized for 14 days before experimentation. The groups were allocated to receive the following: Group 1: Gentamicin only at $80 \mathrm{mg} / \mathrm{kg} /$ day intramuscularly (i.m.) for 10days; Group 2: Gentamicin $80 \mathrm{mg} / \mathrm{kg} /$ day i.m. plus $0.5 \mathrm{mls}$ of B-12 complex $/ \mathrm{kg} /$ day for 10 days; Group 3: Gentamicin $80 \mathrm{mg} / \mathrm{kg} /$ day i.m. plus $1 \mathrm{mls}$ of B-12 complex $/ \mathrm{kg} /$ day for 10 days and Group 4: Sham injection daily for 10 days. B-12 complex (ELDERVIT12, Elder Pharmaceutical Ltd, Mumbai, India (National agency for food and drug administration and control (NAFDAC) number 04-3470) containing the

Shaibu O. Bello, ${ }^{* 1}$ Department of Pharmacology, College of Health Science,Usmanu Danfodiyo University, Sokoto, Nigeria

${ }^{2}$ Ultrasound and Fertility Unit, Karaye Hospital, Emir Yahaya Road, Sokoto, Nigeria.

A. Chika, Department of Pharmacology, College of Health Science, Usmanu Danfodiyo University, Sokoto, Nigeria 
combinations as previously described and Gentamicin sulphate injection (Gentalek ${ }^{\mathrm{R}}$, Lek Pharmaceutical and Chemical company, Veroskova, Slovenia. NAFDAC 040220) purchased from a registered pharmaceutical company were used (stock solution) for the study. The dose of gentamicin used has been consistently demonstrated to induce nephrotoxicity in adult rats (Soliman, et al., 2007) while the dose of B-complex used was the pharmacological equivalent (in rats) of the usual clinical dose in man (Ghosh, 1984). Animals were weighed every alternate day and the last known weight was used for dose calculations. Blood samples were collected by tail bleeding at day zero (day 1 being the day treatment was started) and the other blood samples were collected by cardiac puncture 24 hours after the last injection. Each sample was collected into a sterile sample bottle without anticoagulant and the serum was obtained for analysis. Serum Creatine and Serum Urea were the parameters of interest and were quantified using reagent kits from Bio-Analytics Company (Palm City, U.S.A.). Data was analyzed using Microsoft excel add-on, Analyze-it, and SATS softwares. Student's t- test was used for within group comparison and 1-way ANOVA with Bonferroni error correction was used for between group comparisons.

\section{RESULTS}

There was no significant difference $(P>0.05)$ in the body weight of the animals throughout the duration of the study. There was no significant difference $(P>0.05)$ in the serum creatine and serum urea between the groups at beginning of the study (day 0). In group 2, both the Serum creatine (Fig.1) and Urea (Fig. 2) significantly $(\mathrm{P}<0.05)$ and progressively increased throughout the duration of the study. In group 3 , the serum creatine and urea were significantly $(P<0.05)$ higher than both groups 1 and 2 by day 5 . By day 10 , these values remained higher than group 1 but were significantly $(p<0.05)$ lower than group 2 . In the group 4 , the serum creatine and urea followed these same patterns by days 5 and 10 but were significantly $(\mathrm{P}<0.05)$ lower than groups 2 and 3 (Table 1).

\begin{tabular}{|c|c|c|c|c|c|c|c|c|c|}
\hline \multirow{2}{*}{$\begin{array}{l}\text { Parameter } \\
\text { Group }\end{array}$} & \multicolumn{3}{|c|}{ Weight(g) } & \multicolumn{2}{|c|}{$\begin{array}{l}\text { Serum } \\
\text { (mg/dl) }\end{array}$} & Creatine & \multicolumn{2}{|c|}{$\begin{array}{l}\text { Serum Urea } \\
\text { (mmol/l) }\end{array}$} & \multirow[b]{2}{*}{ Day10 } \\
\hline & Day0 & Day5 & Day10 & Day0 & Day5 & Day10 & Day0 & Day5 & \\
\hline \multirow[t]{3}{*}{ 1. Control } & 194.05 & 182.70 & 193.15 & 1.30 & 1.35 & 1.28 & 6.80 & 6.91 & 7.20 \\
\hline & & & & \pm & \pm & \pm & \pm & & \\
\hline & 15.76 & 26.91 & 18.53 & 0.14 & 0.40 & 0.46 & 0.81 & 1.05 & 2.45 \\
\hline \multirow[t]{3}{*}{ 2. Gentamicin } & 166.03 & 163.90 & 178.95 & 1.33 & *3.38 & *4.78 & 6.95 & *18.28 & *42.18 \\
\hline & & & & \pm & & & \pm & & \\
\hline & 22.21 & 26.91 & 32.72 & 0.22 & 0.22 & 0.46 & 2.07 & 1.01 & 1.18 \\
\hline \multirow[t]{3}{*}{ 3. Gentamicin $+0.5 \mathrm{ml} \mathrm{B-12}$} & 187.73 & 191.15 & 187.03 & 1.43 & *4.33 & *3.75 & 7.08 & *28.23 & *24.75 \\
\hline & & & & \pm & & & & & \\
\hline & 26.30 & 31.52 & 22.31 & 0.16 & 0.85 & 1.39 & 0.15 & 6.21 & 10.79 \\
\hline \multirow[t]{3}{*}{ 4. Gentamicin $+1 \mathrm{mls}$ B-12 } & 172.60 & 164.18 & 173.55 & 1.39 & *3.70 & *2.30 & 6.93 & *21.90 & *15.87 \\
\hline & & & & \pm & & \pm & \pm & \pm & \pm \\
\hline & 11.83 & 13.46 & 21.75 & 0.21 & 0.98 & & & & \\
\hline
\end{tabular}

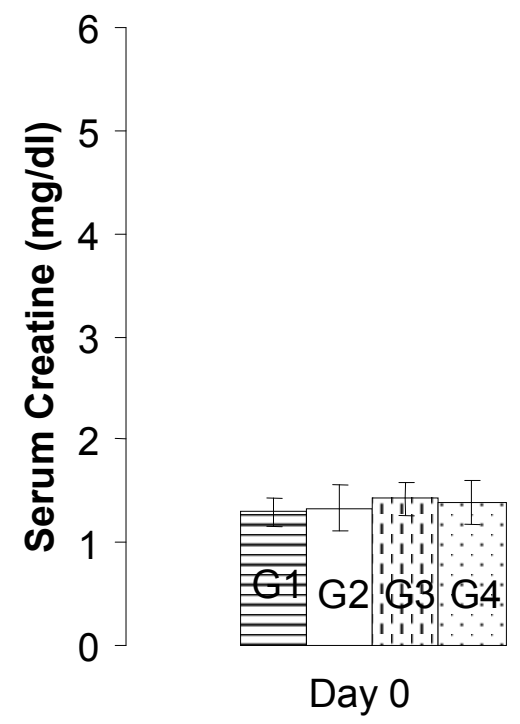

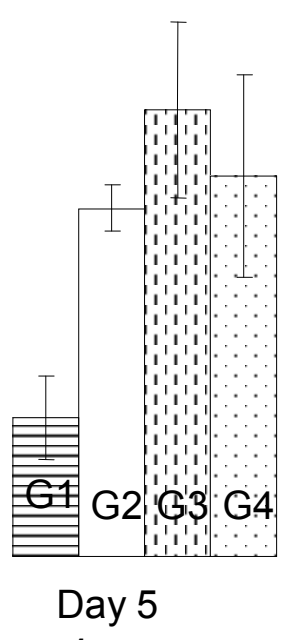

Figure 1

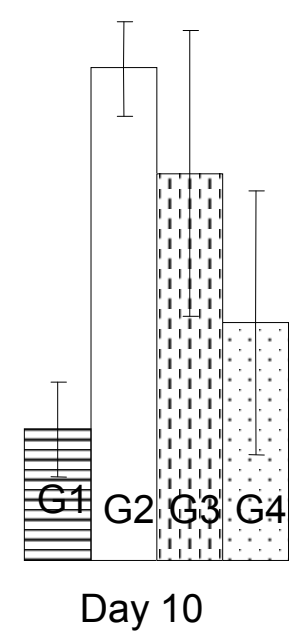




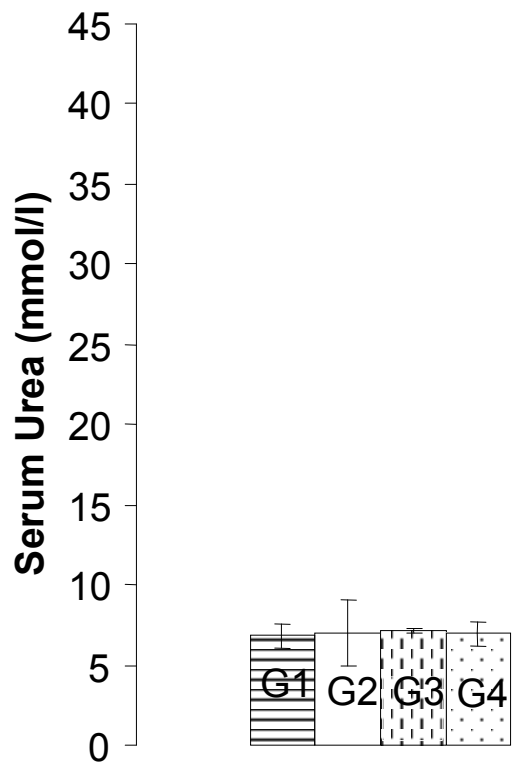

Day 0

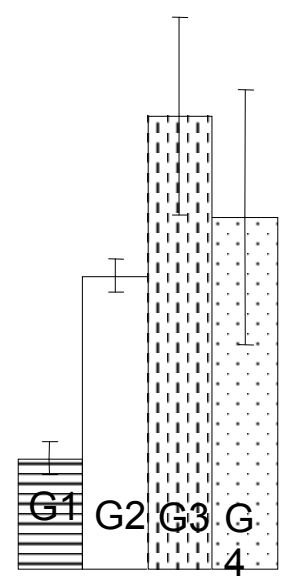

Day 5

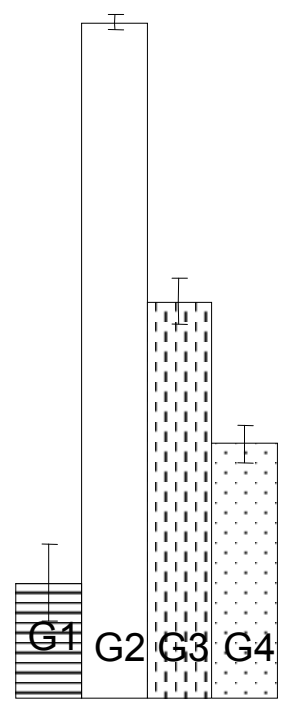

Day 10

Figure 2

\section{DISCUSSION}

Our results showed that $80 \mathrm{mg} / \mathrm{kg} /$ day of gentamicin injection significantly and progressively increased serum creatinine and urea in Swiss albino rats throughout the 10 days of dosing and thus further validate this protocol as a reliable model of gentamicin nephrotoxicity. B-12 complex dose dependently worsened gentamicin toxicity in the first 5 days of dosing but dose-dependently ameliorated gentamicin induced nephrotoxicity in the last 5 days of dosing. This reversal of effect was unpredicted but may be explained by various components of the B-12 complex injection having opposite effects with enhancement of nephrotoxicity being favored on acute dosing and amelioration being favored on longer term dosing. Our data can only be extrapolated to the B-12 complex as a unit but it may be important to recall that of the 5 components of B-12 complex injection, only ascorbic acid has been reported to be nephrotoxic in rats at $1 \mathrm{~g} / \mathrm{kg}$ (Abraham, 2005) though this dose is much higher than the $30 \mathrm{mg} / \mathrm{kg} /$ day and $60 \mathrm{mg} / \mathrm{kg} /$ day of ascorbic acid in the B-12 complex used in this experiment. It is possible that the nephrotoxicity of ascorbic acid operates through a mechanism that synergizes with that of gentamicin. It may be important to conduct further studies to evaluate this hypothesis. Though a number of studies have found dose-dependent nephrotoxicity with many drugs (Greggi-Atunes, et al., 2000, Martinez-Salgado, et al., 2007 ,) at least one study has reported a reversal of effect similar to ours (Appenroth, et al., 1994). Our findings could be of immense clinical importance if confirmed by further studies because it would caution against co-administration of gentamicin and B-12 complex parenterally and suggest that careful evaluation of patients on concurrent treatment with both drugs may be crucial, especially at the initial phase of treatment. The amelioration of gentamicin induced nephrotoxicity in the last 5 days of dosing is reassuring because it occurs in the period that significant gentamicin accumulation and higher incidence of nephrotoxicity is known to occur in man (Gilbert, 1991).

\section{CONCLUSION}

Vitamin B-12 complex injection has an ambiguous effect on the nephrotoxicity of gentamicin which depends on the dose and duration of treatment. It may potentate gentamicin induced nephrotoxicity on short term use and may ameliorate it on longer term administration. These findings are preliminary but clinically important. Further studies are necessary to confirm the findings and to elucidate any histopathological changes that may be associated with the biochemical changes.

\section{REFERENCES}

Abraham, P., 2005. Mega dose of vitamin C augments the nephrotoxicity of paracetamol. Nephrology (Carlton). 10(6):623-4.

Appenroth, D., Winnefeld, K., Schröter, H., Rost, M., 1994. The ambiguous effect of ascorbic acid on chromate induced proteinuria in rats. Arch Toxicol. 68(2):138-41.

Ghosh, M. N., 1984. Fundamentals of Experimental Pharmacology, $2^{\text {nd }}$ ed., Scientific Book Agency, Calcutta, 77pp 
Gilbert, D. N., 1991. Mini-Review: Once daily aminoglycoside therapy. Antimicrob Agents Chemotherapy. 35:399.

Greggi-Antunes, L. M., Darin, J. D., Bianchi, M. D., 2000. Protective effects of vitamin c against cisplatininduced nephrotoxicity and lipid peroxidation in adult rats: a dose-dependent study. Pharmacol Res. 41(4):405-11.

Kadkhodaee, M., Khastar, H., Arab, H. A., Ghaznavi, R., Zahmatkesh, M., Mahdavi-Mazdeh, M., 2007. Antioxidant vitamins preserve superoxide dismutase activities in gentamicin-induced nephrotoxicity. Transplant Proc. 39(4):864-5.

Martínez-Salgado, C., López-Hernández, F.J., López-

Novoa, J.M., 2007. Glomerular nephrotoxicity of aminoglycosides. Toxicol Appl Pharmacol. 223(1):86-98

Rybak, L.P., Ramkumar, V., 2007. Ototoxicity. Kidney Int. 72(8):931-5.

Soliman, K.M., Abdul-Hamid, M., Othman, A.I., 2007. Effect of carnosine on gentamicin-induced nephrotoxicity. Med Sci Monit. 13(3):73-83
LEGENDS TO FIGURES

Figure 1: Effect of Vitamin B-12 injection on the serum G1: Control creatine of Swiss Albino rats

G2: Inj. Gentamicin $80 \mathrm{mg}$ i.m daily for 10 days

G3: Inj. Gentamicin $80 \mathrm{mg}$ i.m daily for 10 days plus inj. B-12, $0.5 \mathrm{mls}$ daily for 10 days.

G4: Inj. Gentamicin $80 \mathrm{mg}$ i.m daily for 10 days plus inj. $\mathrm{B}-12,1 \mathrm{mls}$ daily for 10 days.

B-12: B-12 complex containing $1000 \mathrm{mcg}$ of Vitamin B12 (Cyanocobalamin), 4.8mg of B3 (Niacinamide) and $0.28 \mathrm{mg}$ of Folic acid and $60 \mathrm{mg}$ of Ascorbic acid (Vitamin C) in $1 \mathrm{mls}$

Figure 2: Effect of Vitamin B-12 injection on the serum urea of Swiss Albino rats

G1: Control

G2: Inj. Gentamicin $80 \mathrm{mg}$ i.m daily for 10 days

G3: Inj. Gentamicin $80 \mathrm{mg}$ i.m daily for 10 days plus inj. B-12, $0.5 \mathrm{mls}$ daily for 10 days.

G4: Inj. Gentamicin $80 \mathrm{mg}$ i.m daily for 10days plus inj. B-12, $1 \mathrm{mls}$ daily for 10 days.

B-12: B-12 complex containing 1000 mcg of Vitamin B12 (Cyanocobalamin), $4.8 \mathrm{mg}$ of B3 (Niacinamide) and $0.28 \mathrm{mg}$ of Folic acid and 60 $\mathrm{mg}$ of Ascorbic acid (Vitamin C) in $1 \mathrm{mls}$ 